\title{
Subjetividad y representación. Nota crítica de Categorías y autoconciencia en Kant de Pedro Stepanenko
}

\author{
EFRAÍN LAZOS \\ Facultad de Filosofía y Letras \\ Universidad Nacional Autónoma de México \\ eflazos@servidor.unam.mx
}

\begin{abstract}
ResUMEN: El texto se propone, en primer término, ofrecer una reconstrucción sintética de las principales líneas histórico-interpretativas que de la deducción trascendental ofrece Stepanenko en su libro Categorías y autoconciencia en Kant. En segundo lugar, se discute el llamado problema de las representaciones subjetivas y arguye, en contra del autor, que tal problema no surge en la filosofía teórica de Kant.
\end{abstract}

PALABRAS CLAVE: representación, autoconciencia, subjetividad

La aparición del libro que comento aquí debe ser motivo de festejo. En nuestro tiempo y situación, me parece, no es un libro más de filosofía profesional. Se trata de un libro sistemático y de largo aliento. Esto, que se dice con tan pocas palabras, le permite brillar con luz propia en un mundo intelectual y académico en donde la información está al alcance de los dedos, y en el que la meritocracia salarial favorece, cuando no obliga, a la producción en masa de artículos más o menos breves. No quiero demeritar ni el esfuerzo y el arte de escribir textos filosóficos de poca extensión, ni consiguientemente la costumbre de reunir en un volumen una serie de artículos vinculados por determinada unidad temática. Pero producir un libro como el de Pedro Stepanenko requiere, en una gran medida, nadar a contracorriente. Y esto quiere decir que para ello hacen falta dos virtudes que cada vez son más raras: la paciencia — porque los resultados aparecen muy lentamente- - y la obstinación, o mejor, la perseverancia — porque la empresa parece frecuentemente avasalladora. Dos virtudes que, por cierto, debe poseer y desarrollar cualquiera que se proponga estudiar seriamente la Crítica de la razón pura y, por lo tanto, cualquiera que emprenda la lectura de este libro de Pedro Stepanenko.

De modo que no me parece una exageración afirmar que todo estudioso serio de la filosofía en nuestro país debe celebrar la aparición de Categorías y autoconciencia en Kant. Pero lo celebramos especialmente quienes, por una razón o por otra, hemos estado en la órbita de los estudios kantianos en México. A pesar del indudable y tal vez renovado interés en la filosofía de 
Kant; a pesar de la profusión y alta calidad de los artículos que sobre ella se han producido aquí en los últimos años; y a pesar de valiosas traducciones y antologías, lo cierto es que se echaba en falta un libro sistemático como el que nos ocupa aquí. Hago votos porque éste sea el primero de muchos.

1. En un texto reciente, el propio Stepanenko recurría, con Isaiah Berlin, a las imágenes del erizo y el zorro para caracterizar dos tipos de filosofía y de filósofos. ${ }^{1}$ Los erizos mantienen una idea, defienden con todas sus espinas una sola posición; los zorros, en cambio, son escurridizos, y atacan y se defienden desde distintas posiciones. En nuestra historia, después de una reconstrucción del argumento central del texto, adoptaré provisionalmente la actitud del zorro, porque me parece que en el libro de Pedro Stepanenko, como en la filosofía de Kant, encontramos un ejemplo claro del filósofo erizo. Asumo, entonces, también mis propios riesgos.

Paso ahora a describir brevemente la estructura del texto de Stepanenko. En el primer prólogo de la Crítica de la razón pura [Axvi-xvii], Kant distingue dos facetas de la llamada deducción trascendental de las categorías, esa parte del texto que él mismo consideraba la más importante de la obra, y que es, probablemente, uno de los pasajes más complejos y abstrusos de la tradición filosófica. Por un lado, la deducción trata el tema de los objetos del entendimiento puro y se propone, dice Kant, "demostrar y hacer comprensible la validez objetiva de sus conceptos a priori"; por el otro, trata el tema del entendimiento puro, y las posibilidades y capacidades de conocimiento en las que se basa. Stepanenko nos presenta una minuciosa reconstrucción de ambas facetas, que Kant mismo denominó deducción objetiva y deducción subjetiva. Estudia rigurosamente los escritos precríticos que fueron redactados durante la llamada "década silenciosa" que media entre la aparición de la Dissertatio (Forma y principios de los mundos inteligible y sensible) [1770] y la primera edición de la Crítica [1781]; y nos muestra que ambas facetas de la deducción trascendental pueden considerarse como la pretensión kantiana de unificar dos proyectos distintos. Aquí Stepanenko introduce, lo que en mi opinión es el único punto verdaderamente crítico de su texto: el proyecto kantiano de unificación fracasa, al menos parcialmente.

Pero, ¿en qué consisten ambos proyectos? Y, ¿por qué, según Pedro Stepanenko, Kant no puede unificarlos exitosamente en la primera edición de la Crítica?

2. Si mi lectura es correcta, el primer proyecto se propone probar que los conceptos no derivados de la experiencia pueden ser objetivos, en tanto

1 "Dos imágenes de la actividad filosófica" (inédito). Participación en el encuentro Naturaleza y sentido de la filosofía, Ciudad Universitaria, México, febrero 21 de 2001. 
proveen reglas (a la manera de criterios) para que las representaciones sensibles se refieran a objetos. Es en este proyecto donde se ubica el descubrimiento de un grupo de conceptos no empíricos (la tabla de las categorías) que constituyen las condiciones de posibilidad de la experiencia. Y aquí experiencia se toma como conocimiento de objetos que corresponden a las representaciones de la sensibilidad.

Por otro lado, el segundo proyecto se orienta a demostrar que tiene que haber un conjunto único de conceptos a priori que haga posible la experiencia, donde experiencia es ahora entendida no como el conocimiento de objetos empíricos, sino como la diversidad de representaciones ubicadas en el tiempo. Aquí aparece notoriamente el problemático término kantiano de autoconciencia. Se trata de la conciencia del esquema conceptual bajo el cual integramos cualquier diversidad de representaciones. La idea importantísima que aquí aparece es que no podemos ser conscientes de una representación si no la integramos a este esquema, o en otras palabras, si no se subsume bajo al menos una de las categorías.

Se aprecia entonces que ambos proyectos se dirigen a objetivos diferentes. $\mathrm{Y}$ es en el intento de unificar ambos proyectos donde Kant se enfrenta a lo que Stepanenko llama el problema de las representaciones subjetivas. Así, según el autor, Kant se ve obligado a sostener que toda representación sensible (intuición) se refiere por necesidad a un objeto, dado que las funciones que permiten a esas representaciones referirse a objetos constituyen también las condiciones que hacen posible que seamos conscientes de ellas. Kant parece entonces rechazar la posibilidad de ser conscientes de representaciones que no refieran a objetos (en sentido fuerte), esto es, la posibilidad de representaciones subjetivas.

Stepanenko indica una respuesta a este problema. La solución radica en distinguir dos nociones de autoconciencia. Por un lado, autoconciencia puede entenderse como la conciencia de la actividad de síntesis que emprende el sujeto al aprehender o captar una diversidad; por otro, puede entenderse como la conciencia de la unidad en la que debe ser posible integrar cualquier representación para que tenga un contenido objetivo. Es el modificador modal en esta segunda noción de autoconciencia lo que permite a Kant salvar el problema. No es necesario que todas las representaciones de las que somos conscientes se refieran a un objeto, porque es posible representar un objeto - e.g. en la mera intuición empírica- aún cuando tal representación no esté asimilada y subsumida bajo categorías.

3. Quiero ahora tomar un poco de distancia del texto y preguntarme, por mor de la discusión, si hay en realidad un problema aquí y en qué consiste. El ejercicio no me parece trivial. Si el problema de las representaciones 
subjetivas no es un problema, entonces uno de los principales puntos críticos del texto se desvanece en una excelente y útil reconstrucción.

Veamos a qué refiere el ubicuo término "representación". En primer lugar habría que decir que denota cualquier estado de un sujeto que pueda caracterizarse como mental. Se trata del término Vorstellung, mediante el cual la tradición alemana de la época de Kant pretende dar cuenta de las enigmáticas relaciones entre la mente y el mundo. ${ }^{2}$ Lo que hace una criatura que tiene una mente es representar objetos. Diríamos, para ejemplificar, que cuando alguien cree, juzga, espera, teme algo, el sujeto se representa objetos como poseedores de ciertas propiedades - determinado estado de cosas en el mundo. Según esto, cuando decimos de un sujeto $A$ que teme que un rinoceronte esté a punto de embestirlo, decimos que $A$ se representa un objeto con ciertas propiedades peligrosas, cuando decimos que desea que un rinoceronte esté a punto de embestirlo decimos que $A$ se representa un estado de cosas que de algún modo le sería satisfactorio; cuando decimos que $A$ cree que un rinoceronte está a punto de embestirlo, decimos que se representa un estado de cosas como algo que ocurre de hecho. El objeto de diversas representaciones - aquello acerca de lo cual versan- puede, como en los tres ejemplos, ser el mismo y, en el ejemplo, temor, deseo y creencia comparten un objeto. En este sentido, se podría afirmar que todo estado mental es un estado en el que alguien se representa algo, o, para utilizar un vocabulario tomado de F. Brentano, todo estado mental "incluye un objeto dentro de sí mismo". 3 "Representación" puede entonces significar, por un lado, un estado mental particular - por ejemplo una creencia o un deseoy, por otro, el objeto hacia el cual se dirige ese estado mental -aquello acerca de lo cual versa la creencia. Este último, desde luego, puede tomarse como el contenido de la representación - lo que se expresa después de la cláusula "que" en la atribución de temores, deseos, creencias, etc., a los sujetos.

En la Crítica, la pregunta metafísica sobre la posibilidad de las representaciones se refiere únicamente a aquellas representaciones, como estados mentales, de las que somos conscientes. Kant las llama conocimientos [Erkenntnisse] (cognitios), que, como sabemos, incluyen intuiciones (representatio singularis) y conceptos (representatio discursiva, o per notas communes). ${ }^{4}$ La doctrina trascendental de los elementos puede leerse como una

${ }^{2}$ La tradición británica, por cierto, tiene su propio término, con el mismo cometido, i.e. “idea”. Véase P. Kitcher, Kant's Transcendental Psychology, oup, Nueva York, 1990. pp. 66 y ss.

3 F. Brentano (1874), Psychology from an Empirical Standpoint, trads. Rancurello, D.B. Terrell y Linda McAllister, Routledge \& Kegan Paul, Londres, 1995, p. 88.

4 Esto excluye, de entrada, los deseos y, en general, las representaciones asociadas con la voluntad. Para una clasificación esclarecedora del género "representatio" véase: A320/B376 y Jäsche Logik, p. 96. 
teoría que intenta dar cuenta de esta pregunta. Desde esta perspectiva, la consigna de la doctrina, el famoso dictum kantiano de que "los pensamientos sin contenido son vacíos, las intuiciones sin conceptos son ciegas" [A51 B75], expresa la aspiración kantiana de poner restricciones a lo que ha de contarse como el pensamiento de un objeto. Lo que nos dice la teoría es que para que un pensamiento de que algo es tal y tal sea posible —esto es, para que un pensamiento tenga el contenido que lo identifica como taldebe haber un juego de intuiciones y conceptos. Más allá, lo que la teoría indica que nada puede contar como pensar que $p$, si $p$ no pertenece a un contexto más amplio, o, si se quiere, a un sistema, en el que son pensables otros contenidos. Dicho en términos breves y esquemáticos, los requisitos de objetividad son requisitos de contenido.

Stepanenko tiene claro que la teoría de los elementos - y en particular una de las vetas de la deducción trascendental- es una teoría que ofrece condiciones de objetividad y no condiciones de verdad. Pero, entonces, no resulta muy claro por qué aquí hay algo así como un problema. El autor insiste en la necesidad de hacer espacio para las representaciones subjetivas, i.e. "representaciones que no estén enlazadas con otras conforme a los conceptos que determinan lo que es un objeto..." (p. 178)..$^{5}$ Si lo que las categorías ofrecen son criterios para determinar la verdad de nuestros pensamientos, y no tan sólo el contenido de los mismos, se entiende que preocupe la absurda idea de que, de cumplirse estas condiciones, todo pensamiento sería un pensamiento verdadero. Pero si no es así, ¿en qué radica el problema? Si lo que he sostenido hasta ahora es correcto, el problema tendría que plantearse por la imposibilidad de admitir estados mentales que no tuviesen un contenido representacional, por ejemplo, intuiciones sin conceptos. Esto, sin embargo, es fácil de admitir, siempre que se acepte, como lo quiere Kant, la diferencia de naturaleza entre intuiciones y conceptos. Sería entonces perfectamente posible representar un objeto, intuirlo - como lo harían los niños pequeños, los animales, y tal vez los "salvajes"-, sin que tal representación tenga un contenido, sin que el objeto sea, estrictamente, pensado. Si a esto se le quiere llamar representación subjetiva, todo estará bien; pero no se planteará en realidad ningún problema.

4. En la introducción, Stepanenko indica que su libro se puede comparar con el trabajo de colocar el botón de una camisa. Es difícil acertar en el orificio, pero una vez que lo hemos hecho podemos tirar con confianza del hilo. Lo curioso de la comparación es que guarda afinidades con teoría del retazo (patchwork theory). Es un resultado paradójico y me parece que

5 Véase también, P. Stepanenko, Categorías y autoconciencia en Kant, Instituto de Investigaciones Filosóficas-Universidad Nacional Autónoma de México, México, 2000, pp. 146 y ss. 
es otro de los méritos del texto. Pedro Stepanenko se encuentra entre esos comentaristas que han afirmado que la Crítica es un conjunto abigarrado de retazos de tela, más que un tejido continuo; nos revela un pensamiento en constante movimiento y atacando diversos problemas por diversos flancos, no el pensador monolítico y obsesionado con la simetría de la arquitectura clásica. Nos revela, entonces, un pensador que es mucho más un zorro que un erizo.

Recibido: 17 de mayo de 2001

Aceptado: 25 de junio de 2001 